\title{
Expression of UDP-glucuronosyltransferase 1A4 in human placenta at term
}

\author{
Arne Reimers • Lene Østby • Ina Stuen • \\ Eirik Sundby
}

Received: 8 July 2010/Accepted: 26 November 2010/Published online: 30 December 2010

(C) The Author(s) 2010. This article is published with open access at Springerlink.com

\begin{abstract}
The placenta contains a large variety of metabolizing enzymes, among them UDP-glucuronosyltransferase (UGT). Several UGT2B isozymes have so far been detected in human placenta, but little is known on placental expression of UGT1A isozymes. The antiepileptic drug lamotrigine (LTG) is a UGT1A4-substrate, and its serum concentration falls by over 50\% during pregnancy, leading to impaired seizure control. The placenta may be involved in this. Microsomes from term placentas of 4 LTG-users and 10 healthy control subjects were prepared. Western blot analysis detected UGT1A proteins in all placentas. The presence of UGT1A4 in placenta from LTG users was confirmed with UGT1A4 commercial standard and a specific UGT1A4 primary antibody. Since LTG is primarily metabolized by UGT1A4 and this isozyme is shown to be present in placenta at term, it may be hypothesized that the placenta is involved in the fall of LTG serum concentrations during pregnancy.
\end{abstract}

Keywords UGT $\cdot$ Lamotrigine $\cdot$ Placenta $\cdot$ Microsomes

\footnotetext{
A. Reimers ( $\square)$

Department of Clinical Pharmacology,

St. Olavs University Hospital, P. O. Box 3250 Sluppen,

7006 Trondheim, Norway

e-mail: arne.reimers@legemidler.no

A. Reimers

Department of Neuroscience, Faculty of Medicine,

NTNU, 7489 Trondheim, Norway

L. Østby · I. Stuen · E. Sundby

Sør-Trøndelag University College, Faculty of Technology,

7004 Trondheim, Norway
}

\section{Introduction}

UDP-glucuronosyltransferases (UGTs) are a mammalian superfamily of phase II metabolizing enzymes, of which UGT1A and UGT2B are the most important subfamilies. To date, 25 UGT1A and UGT2B isozymes have been identified in humans (Mackenzie et al. 2005). UGTs catalyze the binding of glucuronic acid to endo- and exogenous compounds, e.g., hormones or drugs. This is an important process that increases their solubility in water and aids in their urinary excretion. UGTs have been found in a variety of organs and tissues, including liver, lungs, intestinal mucosa, brain, uterus and placenta, in both animals and humans (Mackenzie et al. 2005; Myllynen et al. 2005, 2007; Nakamura et al. 2008; Syme et al. 2004).

UGT activity is regulated by various pre- and posttranslational mechanisms, e.g., hormones, liver-enriched transcription factors, ligand-activated transcription factors, and the aryl hydrocarbon receptor (Bock 2010; Ishii et al. 2010). These findings relate mostly to experiments with hepatic UGT. Very little is known on the extent and intrinsic regulation of human placental UGT activity. External factors, e.g., enzyme-inducing drugs, ethinyl estradiol or cigarette smoke may increase UGT activity. Some UGT1A4-substrates, e.g., the antiepileptic drug lamotrigine (LTG), may even induce their own metabolism to a certain degree (Hussein and Posner 1997; May et al. 1996; Ohman et al. 2008; Reimers et al. 2005; Villard et al. 1998).

LTG serum concentrations fall by over $50 \%$ during pregnancy, most presumably due to increased glucuronidation (de Haan et al. 2004; Ohman et al. 2008, 2000; Pennell et al. 2004; Petrenaite et al. 2005). This may lead to loss of seizure control and the necessity to increase the LTG dose (Petrenaite et al. 2005). It is unlikely that pregnancy-induced hemodilution plays a major role in this 
phenomenon as hematocrit usually decreases by only 10-15\% (Klajnbard et al. 2010). Moreover, it has been shown that increased glucuronidation of LTG is the most probable mechanism (Ohman et al. 2008). It is reasonable to assume that most of this glucuronidation takes place in the liver. However, UGT has been found in many other tissues also, including the placenta. The placenta is a major detoxifying organ, protecting the fetus from potentially harmful compounds by means of various enzymes and transporters (Myllynen et al. 2005, 2007; Syme et al. 2004). In contrast to the placental expression of cytochrome P450 enzymes, data on placental UGT expression is scarce. So far, few different isozymes of the UGT2Bfamily have been detected in placental tissue. UGT1A protein expression was found in first trimester human placenta, but not in placenta at term (Collier et al. 2002a, b). Unfortunately, these studies did not distinguish between the different UGT1A isozymes. A more recent study found DNA-transcripts of UGT1A6, but no other UGT1A isozyme, in placental tissue (Zhang et al. 2007).

Since it is unknown where in the body the increased glucuronidation of LTG takes place, and which role the placenta plays in this context, we wished to investigate whether UGT1A4 is expressed in human placenta.

\section{Methods}

\subsection{Placenta specimens and preparation of microsomes}

Placentas from 10 healthy, non-smoking, normal-term pregnant women (controls; samples 1-10) and four nonsmoking, normal-term pregnant women using LTG without enzyme-inducing co-medication (LTG-users; samples 11-14) were taken immediately after cesarean section or vaginal delivery and microsomes of the villous part were prepared within $30 \mathrm{~min}$. Microsomes were prepared by calcium precipitation according to Kamath and Rubin (1972). Briefly, villous tissue from the placenta was homogenized in $0.25 \mathrm{M}$ icecold sucrose and the homogenate was centrifuged at $12,000 \mathrm{~g}$ for $20 \mathrm{~min}$ to obtain a postmitochondrial supernatant (PMS). The PMS was subjected to microsomal aggregation by addition of $\mathrm{Ca}^{2+}$ and then centrifuged again at $27,000 \mathrm{~g}$ for $15 \mathrm{~min}$. The microsomal pellets obtained were suspended in $0.1 \mathrm{M}$ Tris buffer (pH 7.4), added glycerol (final glycerol concentration was $15 \%$ ) and stored at $-80^{\circ} \mathrm{C}$ until use. Preparation of microsomes was performed at $4^{\circ} \mathrm{C}$. The protein concentrations were determined using the Bradford protein assay (Bio-Rad Laboratories), with bovine serum albumin as the protein standard (Bradford 1976).

All study subjects gave their written informed consent. The study was approved by the regional ethics committee.

\subsection{Western blotting}

SDS polyacrylamide gel electrophoresis (SDS-PAGE) was performed according to the method of Laemmli (1970), with minor modifications. Western blot analysis was performed basically according to Towbin et al. (1979). Placental microsomal proteins were denaturated by boiling for 4 min in sample treatment buffer $(0.125 \mathrm{M}$ Tris- $\mathrm{HCl}$, $\mathrm{pH}$ 6.8, $20 \%$ glycerol, $4 \%$ sodium dodecyl sulfate, $0.004 \%$ bromophenol blue, and 10\% 2-mercaptoethanol). Placental microsomal proteins were loaded (30 $\mu \mathrm{g}$ per lane) and separated using 4-20\% linear gradient gel in Tris- $\mathrm{HCl}$ (Bio-Rad Laboratories) for approximately $50 \mathrm{~min}$ at 200 V. Human UGT1A4 supersomes (BD Gentest) were treated in sample treatment buffer analogous to the placental microsomes and then loaded as standard. In addition, human UGT1A1 microsomes (BD Gentest) were loaded as standard. The resolved proteins were transferred electrophoretically to a $0.45-\mu \mathrm{m}$ nitrocellulose membrane (BioRad Laboratories) at $100 \mathrm{~V}$ for $1 \mathrm{~h}$. The nitrocellulose sheets were blocked overnight by treatment with $5 \%$ skim milk in Tris-buffered saline (TBS) containing $0.1 \%$ Tween20. The membranes were rinsed and treated for $1 \mathrm{~h}$ with a 1:1,000 dilution of WB-UGT1A primary antiserum (BD Gentest) or a 1:500 dilution of a specific UGT1A4 primary antiserum (Santa Cruz Biotechnology). The membranes were rinsed four times for $10 \mathrm{~min}$ and incubated for $1 \mathrm{~h}$ with a 1:1,000 dilution of horse radish peroxidase (HRP) conjugated goat anti-rabbit IgG (BD Gentest) or a 1:5,000 dilution of HRP conjugated donkey anti-goat IgG (Santa Cruz Biotechnology), respectively.

Membranes were washed four times with TBS and visualized using Western Lightning Chemiluminescence reagents according to the manufacturer's instructions (BD Gentest and Santa Cruz Biotechnology) followed by light detection on luminescence detection film (Amersham Bioscience).

\section{Results and discussion}

UGT1A proteins were detected, using WB-UGT1A primary antibody, in all four placental samples from women using LTG (Fig. 1a). Two bands were detected in every sample, and one of them co-migrated with the UGT1A4 standard. Western blot analyses with UGT1A4 primary antibody also illustrated the presence of bands, further indicating the presence of the UGT1A4 isozyme (Fig. 1b). The other band detected by WB-UGT1A (Fig. 1a) corresponded to neither the UGT1A4 nor the UGT1A1 standard, which indicates the presence of another isoform of UGT1A in the placenta samples. The WB-UGT1A primary antibody used in this study detects several isoforms of human 
Fig. 1 UGT1A (a) and UGT1A4 (b) protein expression in term placenta from women using lamotrigine. Microsomal proteins were isolated from placental tissue and analyzed by Western blotting with antibodies for the UGT1A protein subfamily (a) or UGT1A4 isozyme (b). 11-14 = microsome samples from four subjects. Equal amounts $(30 \mu \mathrm{g})$ of microsomal total protein were loaded for each lane. Human UGT1A4 supersomes and human UGT1A1 microsomes were used as standards (a). The patterns shown are representative for a series of two or three replicate blots a

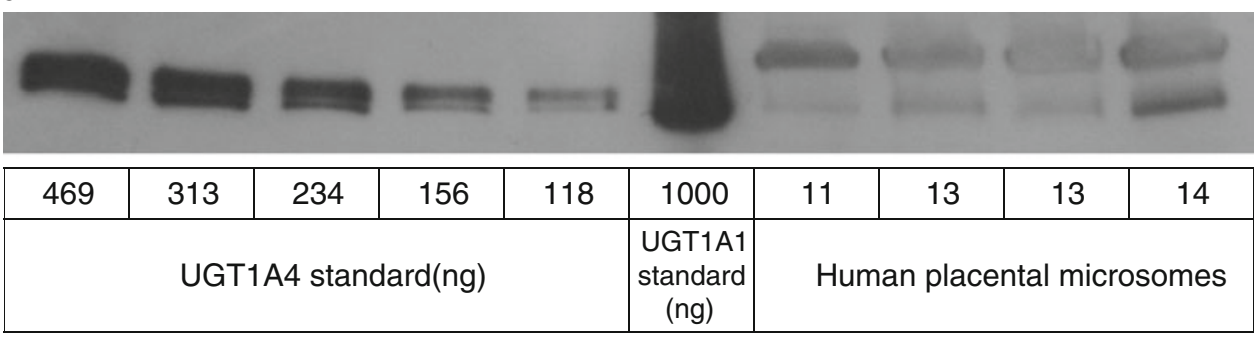

b

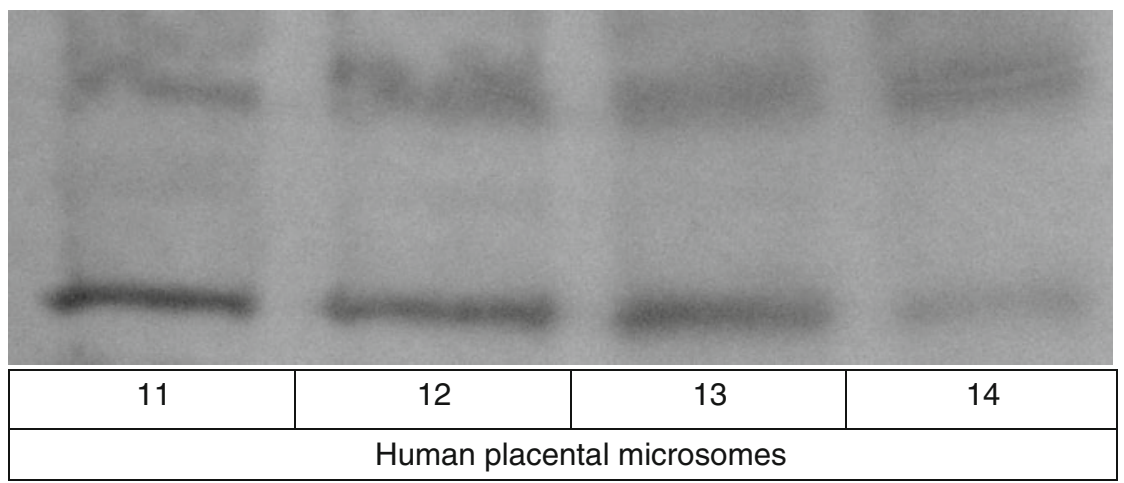

\begin{tabular}{|c|c|c|c|c|c|c|c|c|c|}
\hline 469 & 234 & 118 & 1 & 2 & 3 & 4 & 5 & 6 & 7 \\
\hline
\end{tabular}

Fig. 2 UGT1A protein expression in term placenta from healthy subjects. Microsomal proteins were isolated from placental tissue and analyzed by Western blotting with a specific antibody for the UGT1A protein subfamily. $1-7=$ microsome samples from seven subjects.
Equal amounts $(30 \mu \mathrm{g})$ of microsomal total protein were loaded for each lane. Human UGT1A4 supersomes were used as standards. The pattern shown is representative for a series of two or three replicate blots
UGT1A (UGT1A1, 1A3, 1A4, 1A6, 1A7, 1A9, and 1A10 (mobility range $52-58 \mathrm{kDa})$ ). In a previous study, DNAtranscripts of UGT1A6, but not UGT1A1, UGT1A3, UGT1A4, UGT1A5, UGT1A7, UGT1A8, UGT1A9, and UGT1A10, have been found in human placenta (Zhang et al. 2007). Thus, the unidentified band may be caused by UGT1A6. The fact that this latter study did not find evidence for placental expression of UGT1A4 may be due to considerable methodological differences (DNA-transcripts vs. UGT1A4 protein itself) and the use of a different kind of placental tissue preparation.

UGT1A proteins were also detected in placental samples from the 10 control women not using LTG. A representative immunoblot of microsomes from control women (showing samples 1-7) and UGT1A4 standard is shown in Fig. 2. Although equal amounts of total placental protein and UGT1A4 standard were used in the different immunoblots, weaker bands of UGT1A were detected in the placentas of the control group (Fig. 2), compared to the LTG-user group (Fig. 1). However, our experiments, which were designed to detect UGT1A and UGT1A4 qualitatively, were not suited for quantitative measurements. Moreover, only four placentas were available from LTG-users. Thus, the observed differences in band intensity do not prove real quantitative differences in UGT1A4 expression. It has, though, previously been found that LTG induces its own metabolism (Hussein and Posner 1997). Therefore, it may be hypothesized that LTG-users express higher levels of UGT1A4 than controls due to enzyme induction. Quantitative studies are needed to prove this theory.

UGT1A4 mRNA has previously been found in human liver, stomach, small intestine, colon, kidney, bladder, trachea and ovary, but not in brain, lung, adrenal gland, breast, uterus and testis (Kaivosaari et al. 2007, Nakamura et al. 2008). To our knowledge, our study is the first one to demonstrate UGT1A4 protein in human term placenta. This finding suggests that placental UGT1A4 activity may contribute to the significant fall of LTG serum concentrations during pregnancy. Further studies, e.g., quantitative 
Western blots and metabolizing experiments with placental tissue or whole perfused placentas are necessary to confirm our findings and to evaluate this hypothesis.

Acknowledgments The authors wish to thank Grethe Helde, Mette Moen, $\mathrm{MD} \mathrm{PhD}$, and Eylert Brodtkorb, $\mathrm{MD} \mathrm{PhD}$, for recruiting the women who donated their placenta, and for their help with the logistics around harvesting of the placentas. The skillful assistance of Susanne Hjemaas is kindly acknowledged.

Open Access This article is distributed under the terms of the Creative Commons Attribution Noncommercial License which permits any noncommercial use, distribution, and reproduction in any medium, provided the original author(s) and source are credited.

\section{References}

Bock KW (2010) Functions and transcriptional regulation of adult human hepatic UDP-glucuronosyl-transferases (UGTs): mechanisms responsible for interindividual variation of UGT levels. Biochem Pharmacol 80(6):771-777

Bradford MM (1976) A rapid and sensitive method for the quantitation of microgram quantities of protein utilizing the principle of protein-dye binding. Anal Biochem 72:248-254

Collier AC, Ganley NA, Tingle MD, Blumenstein M, Marvin KW, Paxton JW, Mitchell MD, Keelan JA (2002a) UDP-glucuronosyltransferase activity, expression and cellular localization in human placenta at term. Biochem Pharmacol 63:409-419

Collier AC, Tingle MD, Paxton JW, Mitchell MD, Keelan JA (2002b) Metabolizing enzyme localization and activities in the first trimester human placenta: the effect of maternal and gestational age, smoking and alcohol consumption. Hum Reprod 17:25642572

de Haan GJ, Edelbroek P, Segers J, Engelsman M, Lindhout D, Devile-Notschaele M, Augustijn P (2004) Gestation-induced changes in lamotrigine pharmacokinetics: a monotherapy study. Neurology 63:571-573

Hussein Z, Posner J (1997) Population pharmacokinetics of lamotrigine monotherapy in patients with epilepsy: retrospective analysis of routine monitoring data. Br J Clin Pharmacol 43: $457-465$

Ishii Y, Nurrochmad A, Yamada H (2010) Modulation of UDPglucuronosyltransferase activity by endogenous compounds. Drug Metab Pharmacokinet 25:134-148

Kaivosaari S, Toivonen P, Hesse LM, Koskinen M, Court MH, Finel $M$ (2007) Nicotine glucuronidation and the human UDPglucuronosyltransferase UGT2B10. Mol Pharmacol 72:761-768

Kamath SA, Rubin E (1972) Interaction of calcium with microsomes: a modified method for the rapid isolation of rat liver microsomes. Biochem Biophys Res Commun 49:52-59
Klajnbard A, Szecsi PB, Colov NP, Andersen MR, Jorgensen M, Bjorngaard B, Barfoed A, Haahr K, Stender S (2010) Laboratory reference intervals during pregnancy, delivery and the early postpartum period. Clin Chem Lab Med 48:237-248

Laemmli UK (1970) Cleavage of structural proteins during the assembly of the head of bacteriophage T4. Nature 227:680-685

Mackenzie PI, Bock KW, Burchell B, Guillemette C, Ikushiro S, Iyanagi T, Miners JO, Owens IS, Nebert DW (2005) Nomenclature update for the mammalian UDP glycosyltransferase (UGT) gene superfamily. Pharmacogenet Genomics 15:677-685

May TW, Rambeck B, Jürgens U (1996) Serum concentrations of lamotrigine in epileptic patients: the influence of dose and comedication. Ther Drug Monit 18:523-531

Myllynen P, Pasanen M, Pelkonen O (2005) Human placenta: a human organ for developmental toxicology research and biomonitoring. Placenta 26:361-371

Myllynen P, Pasanen M, Vahakangas K (2007) The fate and effects of xenobiotics in human placenta. Expert Opin Drug Metab Toxicol 3:331-346

Nakamura A, Nakajima M, Yamanaka H, Fujiwara R, Yokoi T (2008) Expression of UGT1A and UGT2B mRNA in human normal tissues and various cell lines. Drug Metab Dispos 36:1461-1464

Ohman I, Vitols S, Tomson T (2000) Lamotrigine in pregnancy: pharmacokinetics during delivery, in the neonate, and during lactation. Epilepsia 41:709-713

Ohman I, Beck O, Vitols S, Tomson T (2008) Plasma concentrations of lamotrigine and its 2- $\mathrm{N}$-glucuronide metabolite during pregnancy in women with epilepsy. Epilepsia 49:1075-1080

Pennell PB, Newport DJ, Stowe ZN, Helmers SL, Montgomery JQ, Henry TR (2004) The impact of pregnancy and childbirth on the metabolism of lamotrigine. Neurology 62:292-295

Petrenaite V, Sabers A, Hansen-Schwartz J (2005) Individual changes in lamotrigine plasma concentrations during pregnancy. Epilepsy Res 65:185-188

Reimers A, Helde G, Brodtkorb E (2005) Ethinyl estradiol, not progestogen, reduces lamotrigine serum concentrations. Epilepsia 46:1414-1417

Syme MR, Paxton JW, Keelan JA (2004) Drug transfer and metabolism by the human placenta. Clin Pharmacokinet 43: 487-514

Towbin H, Staehelin T, Gordon J (1979) Electrophoretic transfer of proteins from polyacrylamide gels to nitrocellulose sheets: procedure and some applications. Proc Natl Acad Sci USA 76: $4350-4354$

Villard PH, Herber R, Seree EM, Attolini L, Magdalou J, Lacarelle B (1998) Effect of cigarette smoke on UDP-glucuronosyltransferase activity and cytochrome P450 content in liver, lung and kidney microsomes in mice. Pharmacol Toxicol 82:74-79

Zhang W, Liu W, Innocenti F, Ratain MJ (2007) Searching for tissuespecific expression pattern-linked nucleotides of UGT1A isoforms. PLoS One 2:e396 